Int. J. Electrochem. Sci., 14 (2019) 9825 - 9837

\title{
Electric Conductivity of Electrolytic Copper Powder Filled Poly(Lactide-co-Glycolide) Composites
}

\author{
Miroslav M. Pavlovićl,*, Radoje V. Pantović ${ }^{2}$,Zoran Janković ${ }^{3}$, Dragan Nedeljković, \\ Nebojša D. Nikolićl ${ }^{1}$ Miomir G. Pavlovićl Jasmina S. Stevanović1, \\ ${ }^{1}$ Institute of Chemistry, Technology and Metallurgy, Department of Electrochemistry, University of \\ Belgrade, Belgrade, Serbia \\ ${ }^{2}$ Technical Faculty in Bor, University of Belgrade, Bor, Serbia \\ ${ }^{3}$ V\&Z Zaštita, d.o.o., B. Luka, Republic of Srpska, Bosnia and Herzegovina \\ ${ }^{4}$ European university, Faculty of international engineering management, Belgrade, Serbia \\ ${ }^{5}$ Center of Excellence in Environmental Chemistry and Engineering - ICTM, University of Belgrade, \\ Belgrade, Serbia \\ *E-mail: mpavlovic@tmf.bg.ac.rs
}

doi: $10.20964 / 2019.10 .02$

Received: 26 June 2019 / Accepted: 3 August 2019 / Published: 30 August 2019

This manuscript presents the results of investigating the properties of composite materials having poly(lactide-co-glycolide) (PLGA) matrix filled with electrolytically produced copper powder whose particles have a highly developed branched structure. The volume fraction of the copper powder used as a filler for the preparation of the composite was varied from 0.4 to $7.2 \mathrm{vol}$. \%. The samples were prepared at $140{ }^{\circ} \mathrm{C}$ by hot molding injection. The effect of the morphology of electrolytically obtained copper powder on the appearance of the percolation threshold and on the conductivity of the composites was studied. Characterization included impedance spectroscopy (IS) measurement of electric conductivity and scanning electron microscopy (SEM), energy dispersive X-ray spectroscopy (EDS), and Fourier-transform Infrared Spectroscopy (FTIR) morphological analysis. Electric conductive pathways were formed throughout the entire volume of the composites, where their formation was purely stochastic in all the dimensions. The percolation threshold was 2.72 vol.\%, which is significantly lower than the one stated in the literature for similar composites, since these kind of composites are investigated for the first time. This property can be attributed to the use of a filler of different, diverse morphologies.

Keywords: electrical conductivity; biodegradable composite material; Poly(lactide-co-glycolide); electrolytic copper powder; FTIR; hardness. 


\section{FULL TEXT}

(C) 2019 The Authors. Published by ESG (www.electrochemsci.org). This article is an open access article distributed under the terms and conditions of the Creative Commons Attribution license (http://creativecommons.org/licenses/by/4.0/). 